\title{
Economically Precise Water Resource Management for Domestic Usage in India
}

\author{
P. Babu, C. Rajasekaran \\ Department of ECE, K. S. Rangasamy College of Technology, Tiruchengode, India \\ Email: pbabu@ksrct.ac.in, raja7ksrct@gmail.com
}

Received 20 April 2016; accepted 10 May 2016; published 2 August 2016

Copyright $(\underset{2016}{ }$ by authors and Scientific Research Publishing Inc.

This work is licensed under the Creative Commons Attribution International License (CC BY). http://creativecommons.org/licenses/by/4.0/

(c) (i) Open Access

\begin{abstract}
In the present years water resource that can be utilized for domestic usage is getting reduced dramatically. In order to have sufficient water for the utilization of future generation, it is our duty to conserve and utilize the available water in a very efficient way. This paper is aimed to help the people to conserve water; it is done with the help of an embedded system that is reconfigurable depending on the number of persons in the family. The system consists of three modules. Each has a different purpose, one module senses the water level present in the tank and intimates the user regarding when the water is needed to be restored. The second module deals with the division of water based on the type of application for which is intended. The third module deals with intimating the municipality regarding the availability of water. All the three modules combine to work in conserving the water; as a result, we can consume nearly $30 \%$ per year per head. So this would result in a large amount of conservation of water. Thus the saved water can be reused for several applications.
\end{abstract}

\section{Keywords}

Water Resource Management, Raspberry Pi, Water Level Sensing, GSM Modem

\section{Introduction}

Enormous growth of developing world has led to huge need of water. Due to unequal distribution of water, sufficient amount of water is not received by few people. Water is said to be another basic need for all the living beings in the earth. Process automation system based upon utilization of an industrial PLC and PC systems including all the network components represents the best way to improve the water distribution technological process [1]. SCADA is one of the emerging technologies which are used for complete monitoring. The overall system is connected to PLC with the help of RS-232 cable [2]. This proposed automated water distribution sys- 
tem is used to distribute the municipal water equally to all street pipe line [3] so that everyone will get the equal amount of water. Here we have explored an idea as solution for the issues such as improper water supply, water quality and over consumption by people. The proposed system is fully automated.

\section{Water Usage and Scarcity}

In India, the design of water supply systems has been done using certain standards. Currently the standard being used is BIS 1172: 1993, reaffirmed in 1998. This specifies a consideration of use of the following:

For communities with a population of between 20,000 to 100,000-100 to 150 litres per head per day.

For communities with a population of over 100,000-150 to 200 litres per head per day.

In its previous avatar there was also an attempt made in IS 1172 to understand the break-up of this demand which was then put as 135 litres per person per day. The break-up was as follows:

Bathing: 55 litres.

Toilet flushing: 30 litres.

Washing of clothes: 20 litres.

Washing the house: 10 litres.

Washing utensils: 10 litres.

Cooking: 5 litres.

Drinking: 5 litres.

\section{Methodology}

According to our work, we are using Raspberry Pi, GSM Modem, Float Sensor and Solenoid valve are the main components of this system. Raspberry Pi is the advance version of ARM11 processor. Using putty configuration it is interfaced on computer and commands are written using Python. We are using latest version of Raspberry Pi that is Model B+ because it supports to the Internet of Things (IOT). GSM Modem is interfaced for communication purpose. Relays are used for the connection of the Raspberry pi and Solenoid valve. Thus, first of all we design water level sensing circuit using Float sensor which measures the level of water in the main tank. Now we send this information of water level to the user through GSM Modem. Solenoid valves are used to split the amount of water into different purpose washing, cooking, bathing, gardening, etc.

The system is implemented when the user get the limited amount of water in home. This water is automated for each application such as washing, cooking, bathing, gardening, etc. The overall block diagram representing our idea is shown in Figure 1.

Raspberry PI is the heart of the project. We have proposed to use "Raspberry Pi B+". The work of the Raspberry in the system is to monitor the level of water stored in the tank and allocate the water accordingly to the intended application and also it will get the input from the user so that the process can be reconfigured.

The water from the corporation reaches each user's home as usual and stored in the main water tank. The water level sensing circuit is interfaced to the raspberry pi processor with the help of inverting amplifier circuit. The level of water stored in the main tank is continuously monitored by the processor and display the water level in the Liquid Crystal Display (LCD).

The solenoid valve distributes the water stored in the main tank for different purpose. Solenoid valve operated in $12 \mathrm{~V}$ and Raspberry pi processor operated in $5 \mathrm{~V}$. So the interfacing of solenoid valve and raspberry pi processor is achieved by the relay and driver circuit.

If the numbers of users in the family get increased, the system is reconfigurable. The reconfiguration is achieved by the keypad and GSM modem. The user sends the message to the municipality regarding their water needs.

The relay circuit is designed to interface the Raspberry pi and solenoid valve. The relay ON and OFF is controlled by the pair of switching transistors (BC 547) shown in Figure 2. The relay is connected in the Q2 transistor collector terminal. The operation of a relay circuit is mentioned in Table 1.

Float is one type of transducer which is used to measure the water level in the tank shown in the Figure 3. The float changes the resistance value depending on the water level. This change in resistance is converted into corresponding voltage signal which is given to inverting input terminal of the comparator. The reference voltage is given to non-inverting input terminal.

The comparator is constructed by the operational amplifier LM 741. The comparator compares with reference 
water level and delivered the error voltage at the output terminal. Then the error voltage is given to next stage of gain amplifier which is constructed by another operational amplifier LM 741. In the gain amplifier the variable resistor is connected in the feedback path, by adjusting the resistor we can get the desired gain. Then the final voltage is given to ADC for converting the analog signal to digital signal. The water level in the tank is identified by microcontroller.

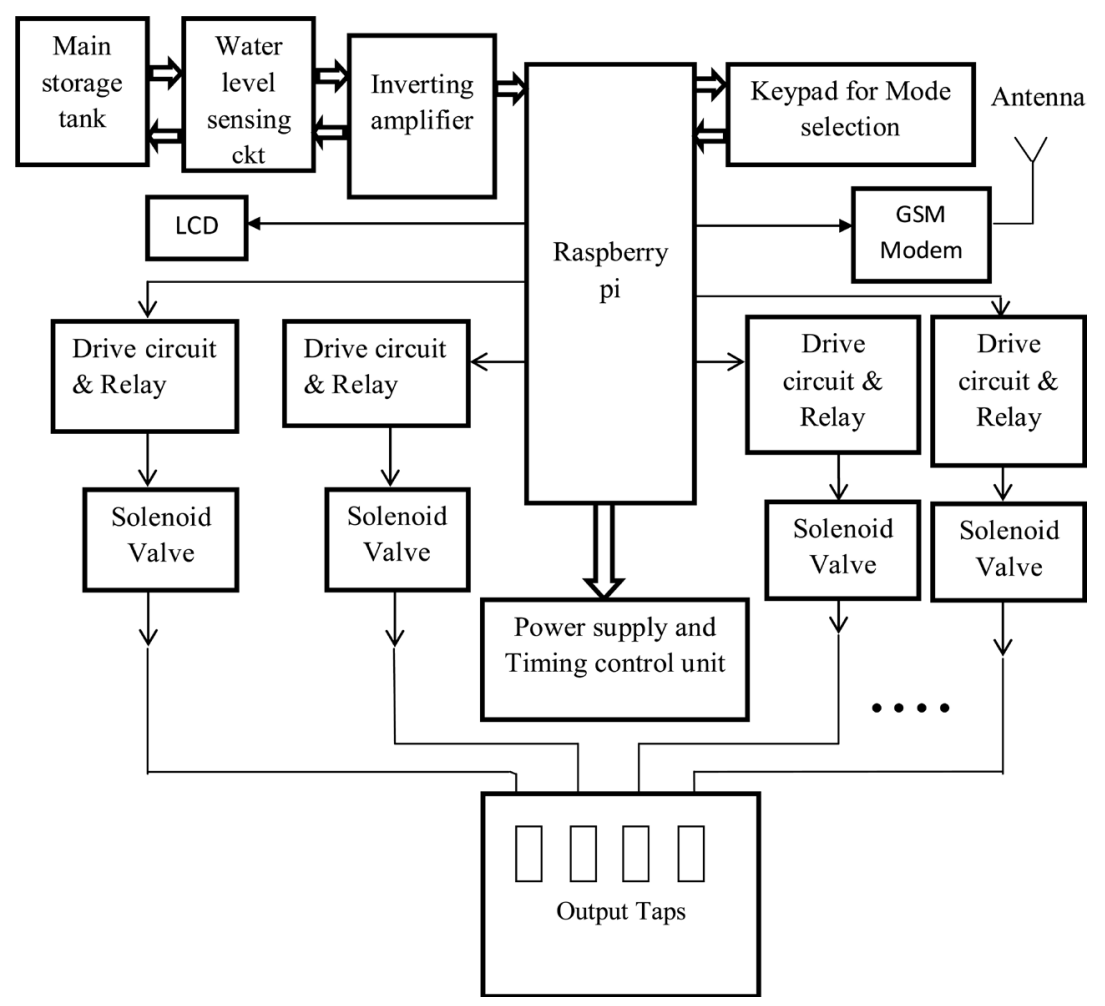

Figure 1. Block diagram of water automatic system.

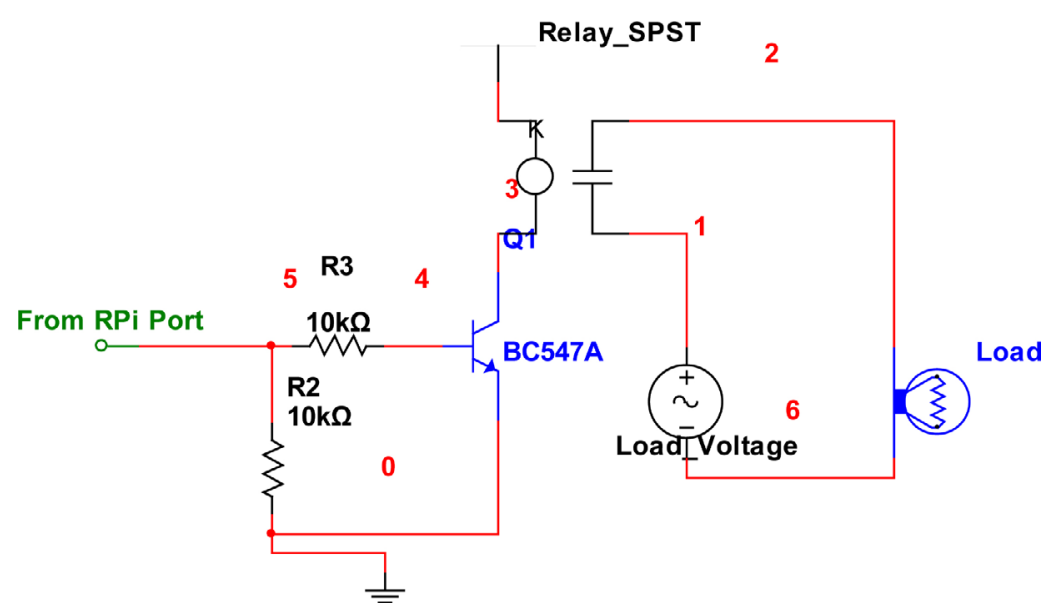

Figure 2. Relay circuit-SPST.

Table 1. Operation of a relay circuit.

\begin{tabular}{cccc}
\hline Voltage Signal from Raspberry PI B+ & Transistor Q1 & Transistor Q2 & Relay \\
\hline 1 & ON & OFF & OFF \\
0 & OFF & ON & ON \\
\hline
\end{tabular}


The water required for the various uses can be given with the help of Solenoid Valve. The work of solenoid valve is to control the flow of water based on the intended application. The function of keypad utilized in the project is to get the information from the user regarding the number of available people in the home, so that water available can be divided for all the members in the family. Also the keypad helps to get the amount of water which is needed. The various needs are like Cooking, Bathing, Washing, Gardening etc.

\section{Hardware Description of Proposed System}

The Hardware of the proposed water automated system consist of three modules shown in Figure 4.The three modules are water level sensing, division of water for each intended application, intimating to the corporation when the number of user in the family get increased.

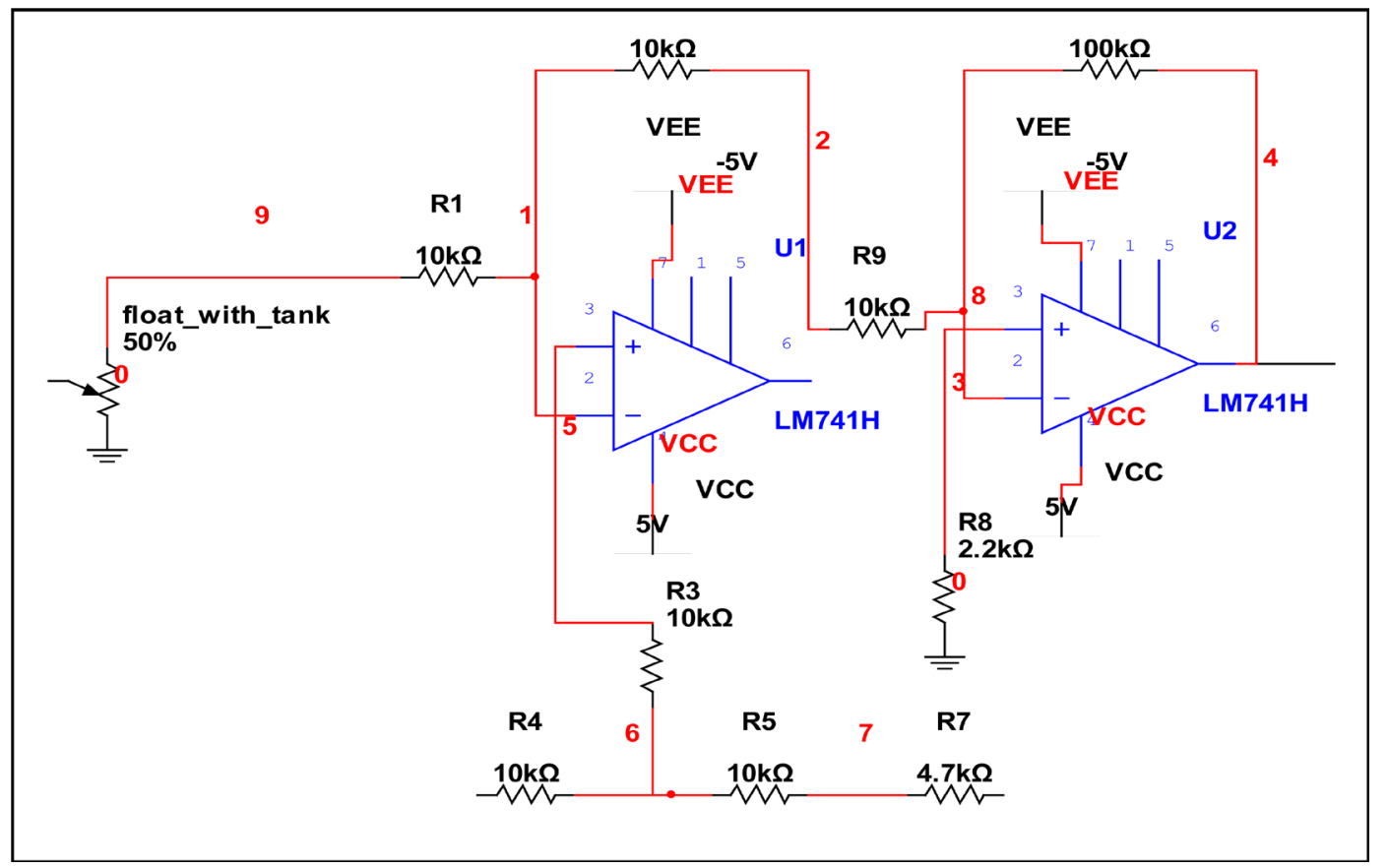

Figure 3. Water level sensing circuit.

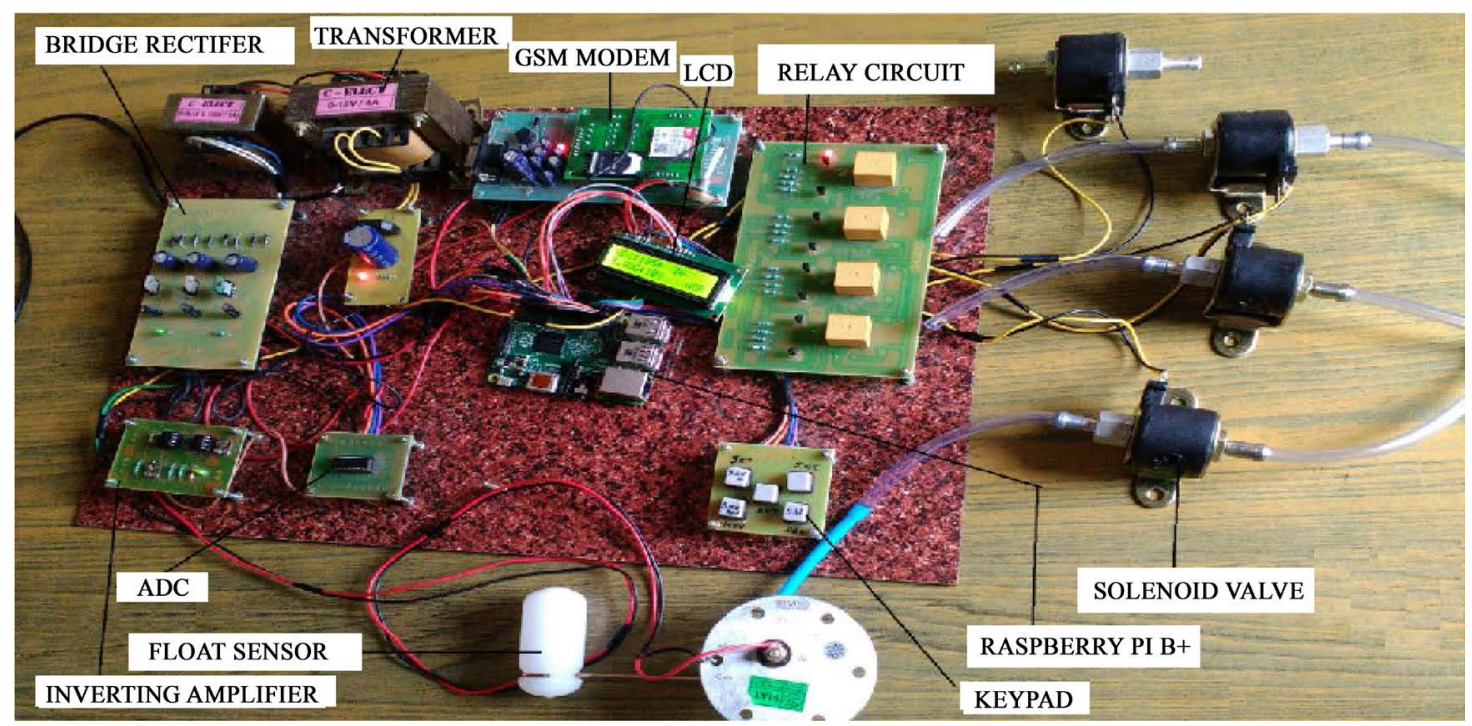

Figure 4. Hardware module of water automatic system. 
Float sensor is used to measure the water level in the main storage tank. Float sensor continuously monitor the water level with the help of variable resistance $(10 \mathrm{~K}, 100 \mathrm{~K})$. The process of water level sensing is shown in Figure 5.

The solenoid valve is used to distribute the amount of water to user needs such as washing, cooking, bathing, gardening, etc. If the number of application is increased, redesign the hardware for the extended application. The proposed method of distribution of water is shown in Figure 6. The amount of water stored in the main storage tank distributed in the taps. In the proposed water supply system each man uses only 135 litres. So each tap release only limited amount of water. For example, bathing tap flows at the rate of 55 litres, Cooking tap flows at the rate of 5 litres, Washing taps flows at the rate of 40 litres and Gardening tap flows at the rate of 35 litres. If the number of application (i.e. user needs or taps) is increased, the system is reconfigurable.

The GSM modem communicates to the user and corporation. Depending on the situation, requirement of water is intimated to the corporation. In the GSM modem, SIM 900 is used. The process of indicating to the corporation through GSM modem is shown in Figure 7.

\section{Hardware Description of Proposed System}

The existing water supply system does not distribute the water equally. This is shown in the Figure 8 . The first user receives the 800 litres. The second user receives 600 litres. The user does not get the equal amount of water.

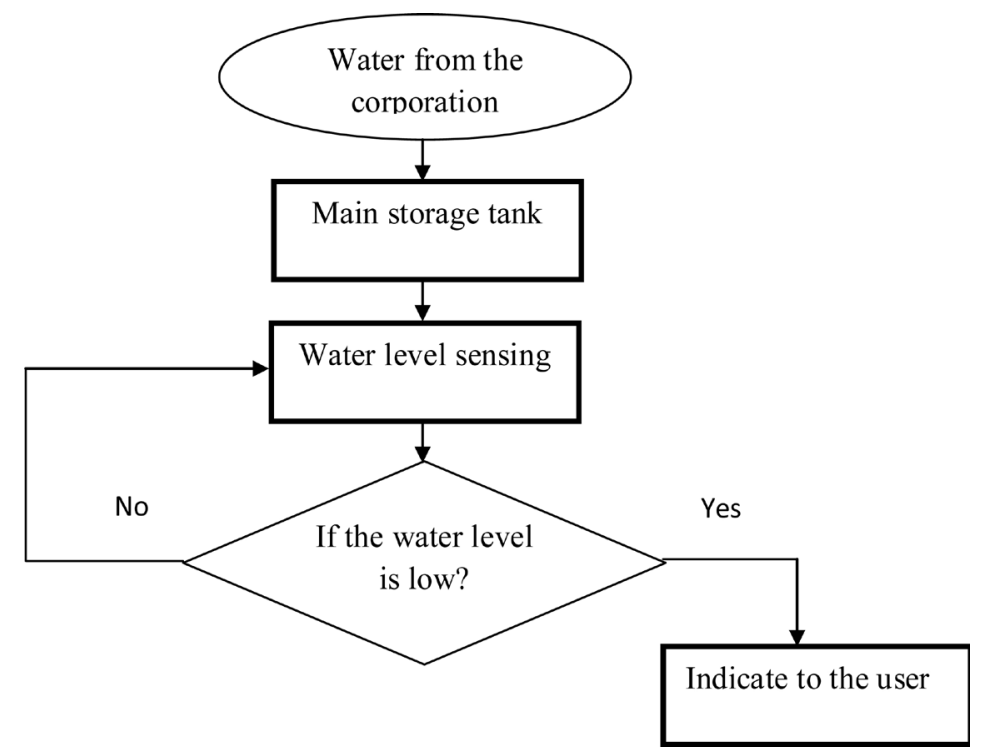

Figure 5. Flow chart of water level sensing.

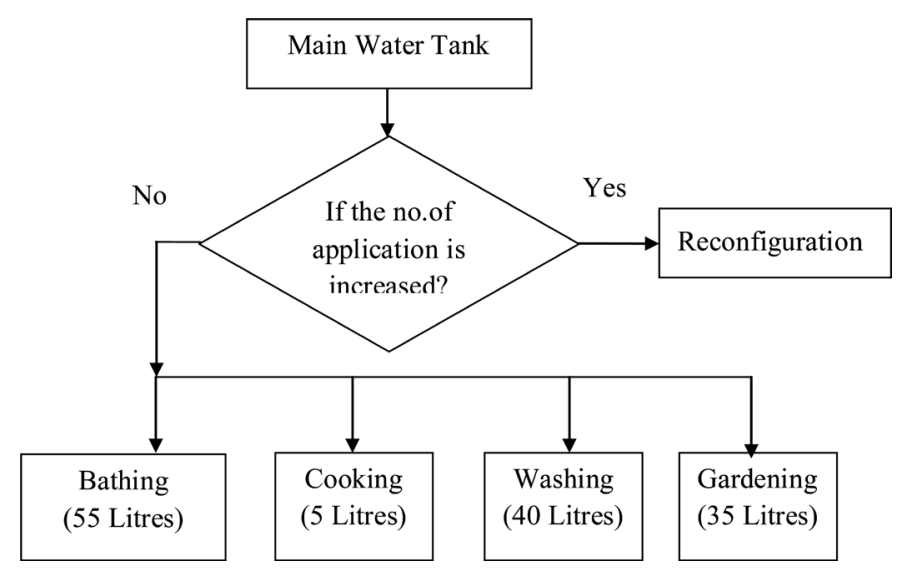

Figure 6. Proposed method of water distribution. 


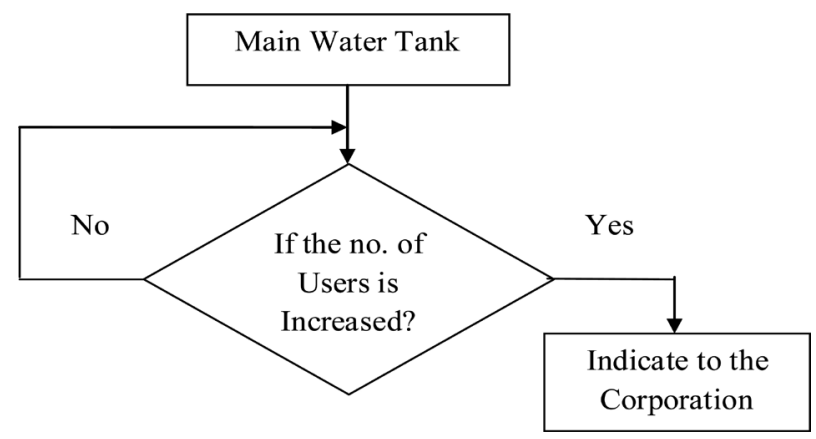

Figure 7. Process of indicating to the corporation.

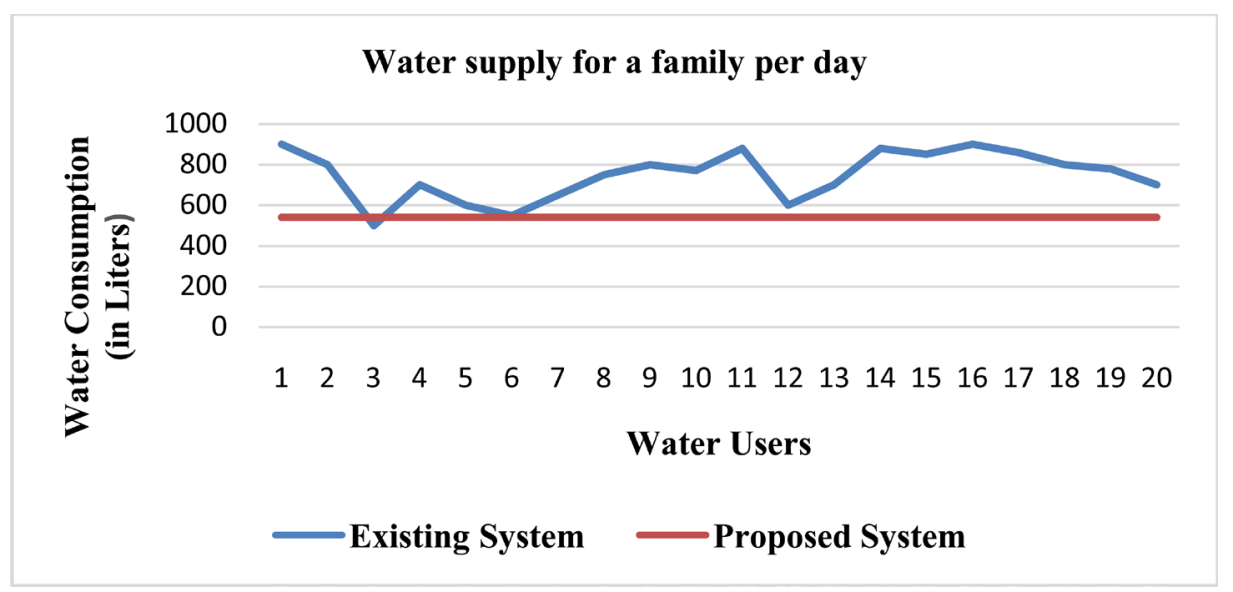

Figure 8. Comparison of existing and proposed water supply system.

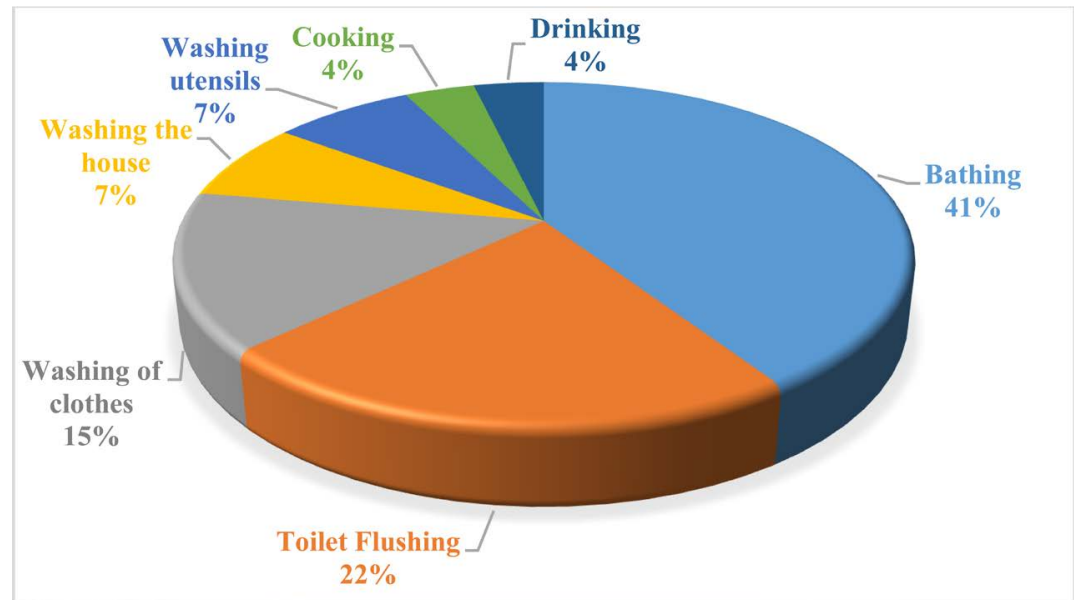

Figure 9. Water usage of a person per day by IS 1172.

This varies depending upon the users. But the proposed system distributes the water equally to all the users. In the Figure 8, each family gets up to 600 litres of water in this proposed system. Each family saves up to 200 400 litres every day.

The IS 1172 mentioned that 135 litres is sufficient for one person per day. The break-up of 135 litres is shown in Figure 9. But every person uses 150 - 200 litres every day. Approximately every person wastes 15 - 65 litres every day (Table 2).

After the distribution of corporation water, the water consumption of an individual person and family has shown in Figure 10 and Figure 11. In existing system the family uses 800 litres of water in a day. But the 
Table 2. Water consumption of a person and family.

\begin{tabular}{ccccccc} 
& \multicolumn{2}{c}{ Existing system water usage (in liters) } & \multicolumn{2}{c}{ Proposed system water usage (in liters ) } & \multicolumn{2}{c}{ Saved water (in liters) } \\
\cline { 2 - 7 } & One person & One family (4 members) & One person & One family (4 members) & One person & One family (4 members) \\
\hline Day & $150-200$ & $600-800$ & 135 & 540 & $15-65$ & $60-260$ \\
Week & $1050-1400$ & $4200-9800$ & 945 & 3780 & $105-455$ & $420-1820$ \\
Month & $4500-6000$ & $18,000-24,000$ & 4050 & 16,200 & $450-1950$ & $1800-7800$ \\
Year & $54,750-73,000$ & $219,000-292,000$ & 49,275 & 197,100 & $5475-23,725$ & $21,900-94,900$ \\
\hline
\end{tabular}

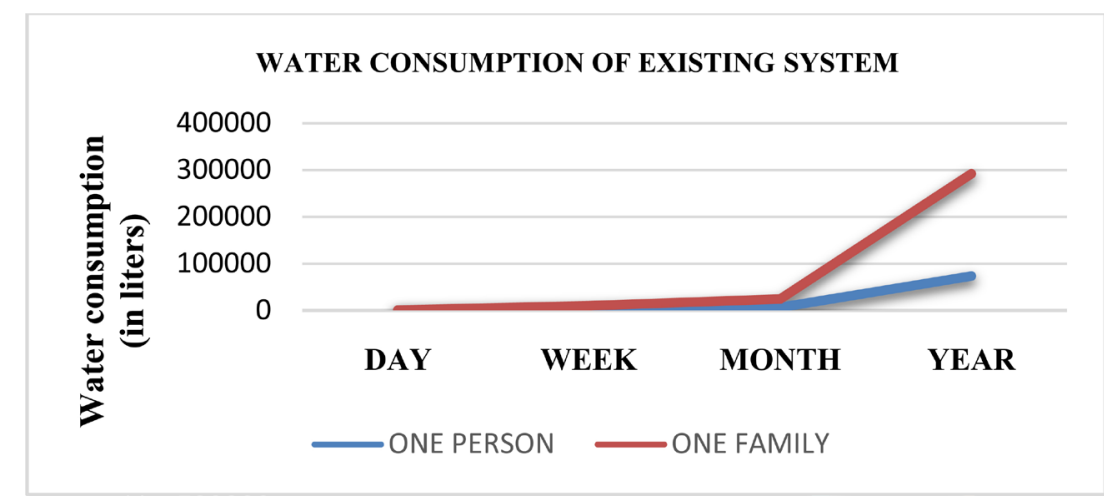

Figure 10. Water consumption of existing system.

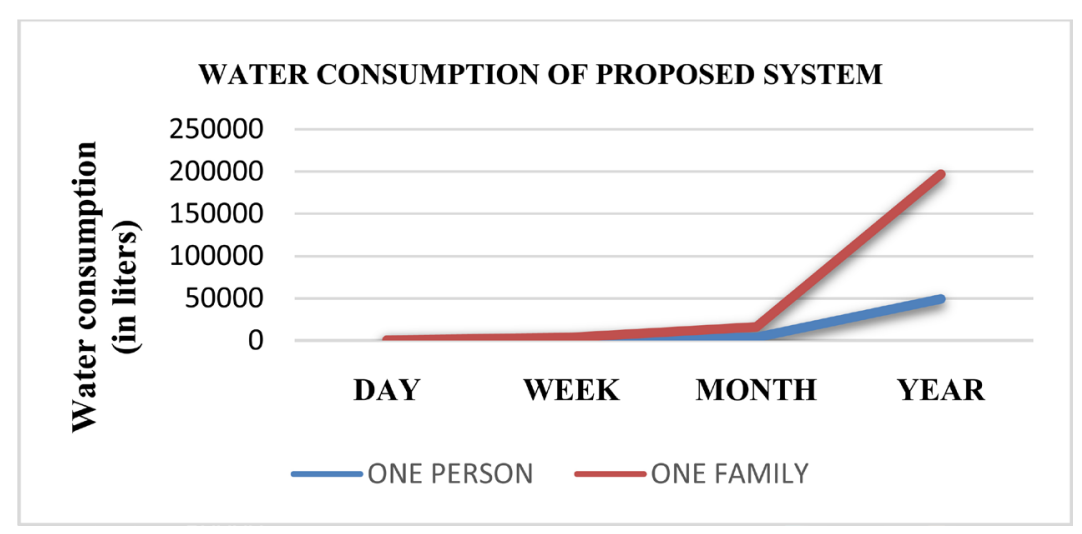

Figure 11. Water consumption of proposed system.

proposed system use only 540 litres. Also the comparison of week, month and year is plotted in the graph.

The existing system uses 292,000 litres in one year. But the proposed system will use 200,000 litres. In one year 92,000 litres of water is saved by each of the family members. Approximately 1/3 (i.e. 33\%) of the water is saved in a year by our proposed system.

\section{Conclusion}

Automated water distribution and performance monitoring system focuses on various entities such as proper supply, over consumption alert and water quality assurance. Automation system provides continuous water flow according to the set point. This system is automatic so it reduces lots of man power. The automation implemented in water distribution system ensures to avoid wastage of water and reduces times so that people could get equal amount of water. This system is excellent and cost effective to prevent the drinking water from the theft during the distribution period. The way in which the water is being utilized is not up to the mark through which water can be conserved, so in order to achieve self-sufficiency in water, we need to be more cautious in conserving the water. Approximately 1/3 (i.e. 33\%) of the water is saved by the proposed automatic water distribution system in one year, thus resulting in large saving of water which can be used to for other applications like home usage, agriculture, etc. 


\section{References}

[1] Gouthaman, J., Bharathwajanprabhu, R. and Srikanth, A. (2011) Automated Urban Drinking Water Supply Control and Water Theft Identification System. Proceedings of the International Conference of the IEEE Student's Technology Symposium, Kharagpur, 14-15 January 2011, 87-91. http://dx.doi.org/10.1109/techsym.2011.5783807

[2] Stancil, E., Stoian, I., Kovacs, I., Gyurka, B.Z. and Balogh, S.Z. (2008) Urban Water Supply Distributed System. Proceedings of the International Conference of the IEEE Automation, Quality and Testing, Robotics (AQTR), Cluj-Napoca, 22-25 May 2008, 316-320. http://dx.doi.org/10.1109/aqtr.2008.4588936

[3] Baranidharan, T., Chinnadurai, A., Gowri, R.M. and Karthikeyan, J. (2015) Automated Water Distribution System Using PLC and SCADA. International Journal of Electrical and Electronics Engineers, 7, 355-360.

\section{Submit or recommend next manuscript to SCIRP and we will provide best service for you:}

Accepting pre-submission inquiries through Email, Facebook, LinkedIn, Twitter, etc.

A wide selection of journals (inclusive of 9 subjects, more than 200 journals)

Providing 24-hour high-quality service

User-friendly online submission system

Fair and swift peer-review system

Efficient typesetting and proofreading procedure

Display of the result of downloads and visits, as well as the number of cited articles

Maximum dissemination of your research work

Submit your manuscript at: http://papersubmission.scirp.org/ 